\title{
Creating visual aids with graphic organisers on an infinite canvas - the impact on the presenter
}

\author{
Jordi Casteleyn*, Andre Mottart and Martin Valcke \\ Department of Educational Studies, Ghent University, Ghent, Belgium
}

(Received 10 June 2014; final version received 28 January 2015)

\begin{abstract}
Instead of the traditional set of slides, the visual aids of a presentation can now be graphic organisers (concept maps, knowledge maps, mind maps) on an infinite canvas. Constructing graphic organisers has a beneficial impact on learning, but this topic has not been studied in the context of giving a presentation. The present study examined this issue by having 199 students prepare a presentation. The control sample created visual aids that are similar to a deck of slides with text and pictures. In the first experimental condition, graphic organisers were inserted in this deck of slides, and in the second experimental condition, visuals aids with interconnected graphic organisers were produced. There were no significant differences in self-reported self-efficacy related to giving a presentation and in motivational variables. To detect if the presentations met the principles set by the conditions, the participants' products were coded qualitatively, but this analysis also yielded no differences in variables. Further research should therefore explore the interaction between software and presenter.
\end{abstract}

Keywords: visual communication; teaching practices; presentation skills; self-efficacy; prezi

\section{Introduction}

\section{The training of presentation skills}

Presentation skills pay a pivotal role in professional life. Therefore, training students to become successful presenters is a major objective in higher education curricula, and researchers have studied several different routes to develop presentation skills, for instance, cooperative learning activities (Chou 2011), goal setting and selfreflection (De Grez, Valcke, and Roozen 2009a) and multimedia-based instructional format (De Grez, Valcke, and Roozen 2009b).

However, the technological dimension of today's presentation possibilities has hardly received attention from researchers in the field of presentation skills training. Studies into educational technology related to presentations primarily discuss its impact on the audience, and mostly do not incorporate reference to the presenter in the analysis. For instance, the Cognitive Theory of Multimedia Learning (CTML) (Mayer 2009) summarises the research-based principles to design effective visual aids, but this has not been connected to a speaker's presentation skills.

*Corresponding author. Email: jordi.casteleyn@ugent.be 


\section{J. Casteleyn et al.}

\section{Presentations with graphic organisers}

Regarding the 'sophisticated software' aspect of presentations, most would refer to slideware software such as Microsoft's PowerPoint, Apple's Keynote or OpenOffice's Impress, but since 2009 new opportunities to represent information visually during a presentation have become freely available. Different from slideware programs, the web-based presentation tool Prezi gives the user a single infinite canvas to create presentations in a non-linear way. One can group the visual elements into frames and zoom in and out on these objects (N.N. 2012). A direct link can be established between these Prezi features and the educational concept of concept maps, knowledge maps, mind mapping and non-linguistic representations. In line with Shaw and colleagues' study (Shaw et al. 2012), we however want to use 'graphic organisers' as a general term to denote these 'displays that visually represent relationships among specific concepts in text' by spatially arranging those concepts. Slideware software can also help to visualise some of these relationships, but programs such as Prezi are not limited by the constraints of consecutive slides and therefore are better able to represent a complete presentation via graphic organisers in one single 'slide'.

Two earlier studies examined how graphic organisers on an infinite canvas (viz. the design of the presentation) could affect the learning process and the audience appreciation of the presentation. In both studies, the experimental condition of graphic organisers on an infinite canvas was compared to a version which conveyed the same information, was in line with the principles of CTML, and did not use graphic organisers. The results from a study involving social science students indicated that there was no statistically significant difference in knowledge acquisition, cognitive load and self-efficacy, but that the participants preferred the version with the graphic organisers to the control sample (Casteleyn, Mottart and Valcke 2013). In a related study involving secondary education students, also no differences in knowledge acquisition, cognitive load and self-efficacy could be reported, but the version with graphic organisers was perceived as less useful (Casteleyn and Mottart 2012).

\section{Creating presentations with graphic organisers}

The impact on presentation skills

From the perspective of the audience during a presentation, it appears that the additional value of graphic organisers currently is unclear. Additionally, no research could be uncovered that focuses on enhancing presentation skills by asking participants to create graphic organisers on a single infinite canvas. However, a metaanalysis conducted by Nesbit and Adesope (2006) reports a substantial positive effect of constructing graphic organisers on learning in different geographical locations, under various conditions, and for different types of interpersonal interaction.

We explored the differential impact of creating a presentation with graphic organisers on infinite canvas on the competence to give a presentation, and decided to employ self-reported self-efficacy related to presentation skills as a dependent variable for this study. Self-efficacy, which can be defined as 'the individual belief in the possibility to do a specific task or to show specific behaviour' (Bandura 1977), can be regarded as a significant determinant of personal behaviour and behavioural change. In education, self-efficacy plays an important role, because a directly proportional link between a high self-efficacy level and learning performance has 
long been established (Graham and Weiner 1996). Compared to creating presentations without graphic organisers, creating graphic organisers for a presentation should better enhance the speaker's learning and knowledge of the topic and consequently increase the self-efficacy regarding presentation skills. Compared to creating presentations with graphic organisers limited to 'slides' (or 'frames' in a Prezi context), designing interconnected graphic organisers for a presentation should have an even larger impact on the presenter's self-efficacy regarding giving a presentation, because the presentation's content is represented in one single graphic organiser, which should be easier to comprehend. It is vital to stress that in this study, selfefficacy is confined to the topic of presentation skills and does not refer to specific features of an assignment or to more general learning outcomes.

\section{The impact on motivation}

Although constructing graphic organisers for a presentation might enhance the speaker's self-efficacy regarding giving a presentation, 'even highly efficacious people may experience less than optimal well-being if they pursue and successfully attain goals that do not fulfil basic psychological needs' (Ryan and Deci 2000). However, intrinsically motivated activities form the basis for people's learning and development (Deci and Vansteenkiste 2004). An additional beneficial feature of constructing graphic organisers however is the reduction in anxiety (Novak 1990). The presenter builds a hierarchically organised network of concepts, is able to convey the information into another context and, thus, feels more in control. This is a 'strong positive intrinsic motivation for the learner, in contrast to the extrinsic motivation that derives from rote learning where the primary dividend is a high test score' (Novak 2010). This intrinsically motivating feature of constructing graphic organisers can be connected to the self-determination theory, as described by Ryan and Deci (2000). Discussing the complete spectrum of human motivation, this theory identifies four categories within externally motivated behaviour: external regulation, introjected regulation, regulation through identification, and identified regulation. The most autonomous form of this extrinsic motivation is the latter category which is fully assimilated into the self. The qualities associated with integrated regulation (e.g. interest, enjoyment, inherent satisfaction) are the same as to the ones found with intrinsic motivation, but integrated regulation refers to external outcomes. One might expect that creating graphic organisers on an infinite canvas better enhances the integrated regulation related to giving a presentation.

\section{Research hypotheses}

Rooted in the theoretical framework described above, the following research hypotheses were formulated:

- Compared to creating a presentation without graphic organisers (WGO condition), creating a presentation with graphic organisers will result in an improvement of the self-reported self-efficacy regarding presentation skills. Concerning this, the condition with interconnected graphic organisers (IGO condition) will also score better than the condition with graphic organisers limited to frames (GO condition). 
- Compared to creating a presentation without graphic organisers (WGO condition), creating a presentation with graphic organisers will result in an increase of the participants' integrated regulation to train their presentation skills. Concerning this, the condition with interconnected graphic organisers (IGO condition) will also score better than the condition with graphic organisers limited to frames (GO condition).

\section{Method}

To test our hypotheses, we organised seminars on presentation skills, during which the participants created presentations following the design principles of each condition (without graphic organisers, graphic organisers limited to frames or interconnected graphic organisers). Each condition was randomly assigned to a seminar, and each seminar was organised in an identical way. Participants were asked to prepare and eventually give a presentation, but they first received instructions on how to create an effective presentation via an e-lecture.

\section{Context and participants}

The study was set up in the context of the course 'Instructional Sciences' at Ghent University (Belgium). Most participants were undergraduate students for whom it was the first experience with experience-oriented research in an experimental setting. However, they were familiar with the online learning environment of the university and had already been asked to complete other surveys in the context of another study. The lecturer communicated the experiment as a seminar on presentation skills and announced that attendance was obligatory. Students received a credit in return.

\section{Material design}

Two e-lectures were created to convey the instruction to the participants. The first e-lecture was used in the WGO condition, the second one in the GO and in the IGO conditions. Both e-lectures gave the same introduction into the user interface of the Prezi website and summarised the general principles concerning the creation of visual aids, referring to the CTML. The WGO video however delivered additional background on the theory underpinning these principles, whereas the GO and IGO e-lecture demonstrated the different types of graphic organisers as another means of representing information during a presentation, such as descriptive patterns and process/cause-effect patterns. This latter section was based upon the chapter on nonlinguistic representations as can be found in Marzano, Pickering and Pollock (2001). Both e-lectures had a similar length of time.Both e-lectures can be accessed online:

- WGO video: http://vimeo.com/52746643 (24.33 minutes)

- GO and IGO video: http://vimeo.com/52754650 (25.51 minutes)

As Dutch is the native tongue of most of the participants, the e-lectures were in Dutch. Moreover, the presentation that participants had to prepare in the seminar also had to be in Dutch. Concerning presentation skills, this aspect is vital, because 
Tsai (2010) detected that foreign language proficiency has an effect on students' presentation skills.

It is also important to emphasise that following the e-lecture participants in the GO condition were asked to create a presentation that consisted of a set of frames in which graphic organisers were used, whereas participants in the IGO condition were asked to produce a presentation in which all the graphic organisers were interconnected.

\section{Research instruments}

Several research instruments were employed to measure the dependent variable (selfreported self-efficacy regarding presentation skills) and the motivational variables (focusing on external regulation, introjected regulation, identified regulation and integrated regulation). In addition to this, participants indicated the number of minutes they had worked upon the presentation, and reported which percentage of their preparation time was devoted to issues related to content (understanding the topic, selecting information etc.), design (creating the visual aids, structuring the presentation etc.) and other items.

To determine the self-reported self-efficacy concerning presenting, a new scale was developed. Twenty one items were selected to represent the complete set of auxiliary skills and knowledge items needed to deliver a quality presentation. For instance, 'I can adopt a good body composure during the presentation'. For each item, participants were asked to give a score - on a scale of $0-100$ - to the degree of which they feel certain they master this skill or knowledge item. A panel of experts on the subject of presentation skills reviewed and approved the test before introducing it into our study. The same survey was used at both test moments. Cronbach's alpha of this test $(\alpha=0.978$ for the first administration and $\alpha=0.964$ for the second administration) indicates a high reliability.

Vansteenkiste et al.'s scales (Vansteenkiste et al. 2009) were duplicated in this research study to detect the motivational variables. Special attention was given to relate the different items in the scales to the learning of presentation skills, and therefore not to construct scales which only have a reference to learning in general. Participants were asked to score the different items on a five-point Likert scale.

During the experiment, we asked our participants to use the Prezi website to create their presentations. As we hypothesised that there would an unequal amount of prior knowledge concerning the website's user interface, a test was created to detect the participant's IT skills related to this presentation tool. Similar to the self-reported self-efficacy test concerning presentation skills, 21 items were chosen, but now we based ourselves on the website's learning section (N.N. 2012) to select the elements which are essential to complete the assignment of the experiment satisfactorily. For instance, 'I can move objects such as arrows and lines in a Prezi presentation'. Cronbach's alpha of this test $(\alpha=0.964)$ shows a high reliability.

\section{Research procedure}

For this experiment, a pre-test-post-test design was used, with the WGO condition (creating a presentation without graphic organisers) as control sample, and two experimental conditions, viz. the GO condition (creating a presentation with graphic 


\section{J. Casteleyn et al.}

organisers limited to frames) and the IGO condition (creating a presentation with interconnected graphic organisers).

The week prior to the experiment, each participant was invited to finish four administrative tasks. This is test moment 1 for the dependent variable and the variables related to motivation. Following this, we randomly assigned the conditions to seminars, and due to this, the exact features of the seminars remained undisclosed to participants. Figure 1 gives an overview of the structure of the seminars.

All seminars were organised in the IT room of the faculty, lasted 2.5 hours and started with a short introduction during which an overview of the seminar was given. To ensure the link between the seminar's content and the reality of presenting, we constantly emphasised that a number of students would give a 3- to 5-minute presentation to their peers at the end of the seminar. They were asked to give an overview of the different types of learning, more specifically on the development of declarative and procedural knowledge. During classes, the lecturer had already discussed this topic, and we referred to the pages in the course book for extra information. This topic was selected because it has been demonstrated to pose cognitive problems to most students, and therefore a low prior knowledge could be guaranteed among participants. In the context of a lecture, low prior knowledge students learn more when graphic organisers accompany the lecture than when key terms are listed (Lambiotte and Dansereau 1992).

Participants were then given a booklet with all necessary instructions for the rest of the seminar, and proceeded to complete the survey on the self-perceived skills related to the specific presentation tool used in this seminar (i.e. test moment for the self-efficacy of IT skills). Following this, they turned to the e-lecture at the university's online learning environment. The participants then received a handout with the most important information from the e-lecture: the general principles for creating a presentation (for all conditions), and the examples of graphic organisers used in the

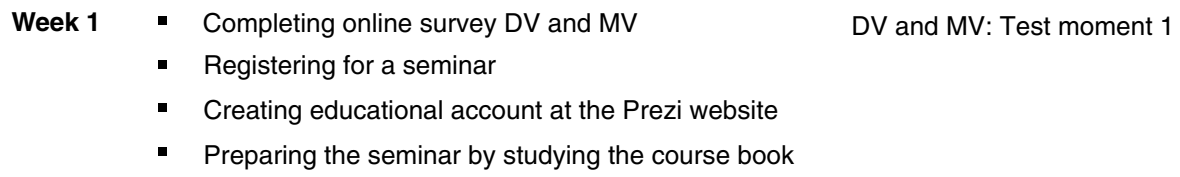

- Posting link to presentation on the forum

- Completing survey DV and MV

DV and MV: Test moment 2

$2.15 \mathrm{~h} \quad$ Participants giving their presentations

$2.30 \mathrm{~h} \quad$ End of the seminar

Figure 1. Overview of the seminar's structure. 
e-lecture (for the GO and IGO conditions). They were also given a picture to illustrate what the design of their presentation should be: a set of frames (WGO, see Figure 2), a set of frames with graphic organisers (GO, see Figure 3) and IGO (IGO, see Figure 4). Students then moved to the Prezi website to create their presentations. On average, they had 90 minutes to complete this assignment. Two hours into the seminar, participants were reminded to round-off their preparation, put the link on the seminar's forum of the university's online learning environment and complete the second survey (i.e. test moment 2 for all variables). To decrease interference, each seminar had its own forum, and forums were made unavailable to participants after each session. We then randomly selected a number of students who gave the presentation they had prepared to the rest of the participants. In general, three presentations per session were delivered. This concluded the seminar.

\section{Results (based on the conditions, namely creating different types of presentations)}

Although 231 students were officially registered in the course, only 199 students completed the surveys at test moment 1 (male: 18; female: 171; average age: 19.19 years). However, 219 students participated in the actual experiment and filled in the ques-

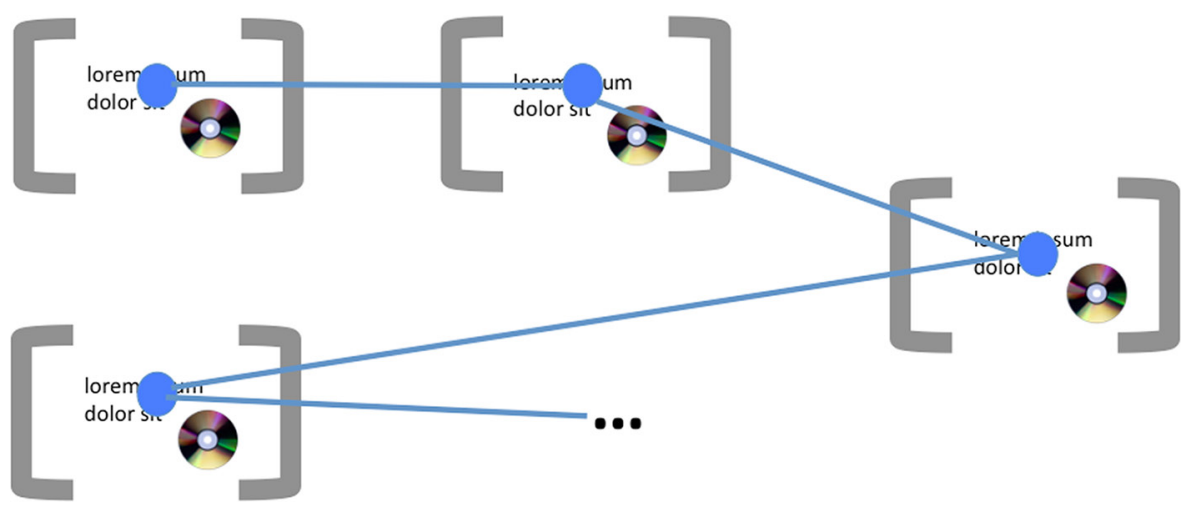

Figure 2. Creating a presentation without graphic organisers (WGO condition): example in booklet.

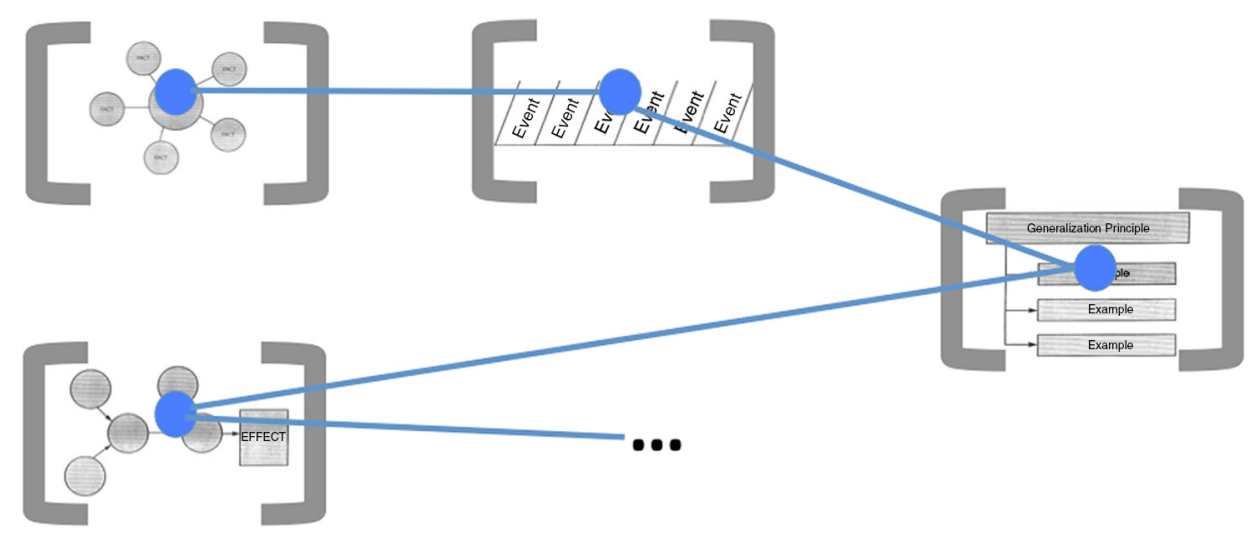

Figure 3. Creating a presentation with graphic organisers (GO condition): example in booklet. 


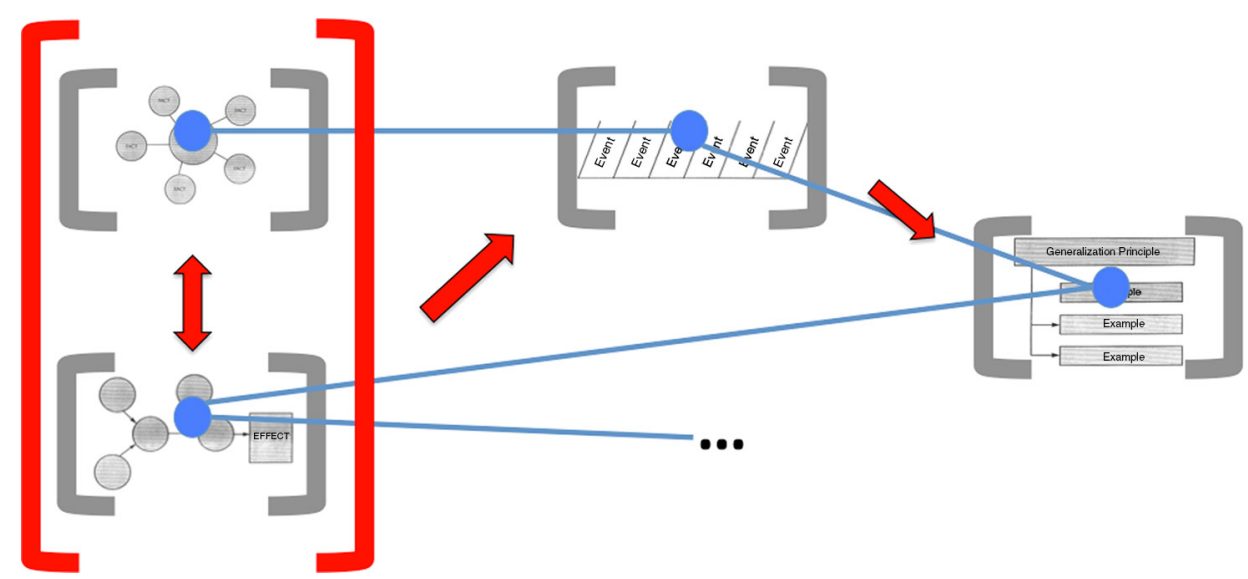

Figure 4. Creating a presentation with interconnected graphic organisers (IGO condition): example in booklet.

tionnaires at test moment 2. These additional entries were removed from the final data set. Moreover, not all students were thoroughly strict in completing the surveys, which sometimes lead to partial answers and, comparing the variables in this study, to an unequal number of participants across conditions.

Table 1 gives an overview of the descriptive statistics of the different variables at test moment 1 and 2. It also summarises the number of minutes spent on the assignment and the self-reported percentages on content, design and other items.

Table 1. Descriptive results (based upon the conditions).

\begin{tabular}{|c|c|c|c|c|c|c|c|c|c|}
\hline & \multicolumn{3}{|c|}{$\begin{array}{l}\text { Without graphic } \\
\text { organisers } \\
\text { (WGO) }\end{array}$} & \multicolumn{3}{|c|}{$\begin{array}{c}\text { Graphic } \\
\text { organisers limited } \\
\text { to frames }(\mathrm{GO})\end{array}$} & \multicolumn{3}{|c|}{$\begin{array}{c}\text { Interconnected } \\
\text { graphic } \\
\text { organisers (IGO) }\end{array}$} \\
\hline & $N$ & $M$ & SD & $N$ & $M$ & SD & $N$ & $M$ & SD \\
\hline Total time spent (minutes) & 75 & 73.56 & 10.16 & 47 & 72.57 & 16.54 & 63 & 74.75 & 12.33 \\
\hline Time spent on content $(\%)$ & 76 & 45.84 & 16.62 & 49 & 38.31 & 21.05 & 67 & 36.81 & 19.29 \\
\hline Time spent on design (\%) & 76 & 40.34 & 16.92 & 49 & 46.43 & 21.59 & 67 & 50.1 & 19.45 \\
\hline Time spent on other times $(\%)$ & 74 & 8.46 & 8.28 & 48 & 8.8 & 8.82 & 64 & 8.22 & 7.04 \\
\hline Self-efficacy IT skills & 76 & 16.69 & 24.92 & 48 & 19.51 & 21.98 & 66 & 14.93 & 23.83 \\
\hline Self-efficacy presenting (t1) & 78 & 63.43 & 16.11 & 50 & 58.96 & 19.15 & 70 & 64.13 & 13.43 \\
\hline Self-efficacy presenting (t2) & 75 & 57.9 & 15.45 & 49 & 57.65 & 13.97 & 67 & 61.67 & 10.06 \\
\hline Change in self-efficacy presenting & 75 & -5.79 & 18.28 & 49 & -2.39 & 17.3 & 67 & -2.6 & 14.10 \\
\hline External regulation $(\mathrm{t} 1)$ & 78 & 2.7 & 0.71 & 50 & 2.67 & 0.82 & 70 & 2.63 & 0.82 \\
\hline External regulation (t2) & 75 & 2.7 & 0.85 & 49 & 2.58 & 0.78 & 67 & 2.57 & 0.87 \\
\hline Change in external regulation & 75 & 0.02 & 0.64 & 49 & -0.1 & 0.85 & 67 & -0.04 & 0.71 \\
\hline Introjected regulation (t1) & 77 & 2.43 & 0.95 & 48 & 2.19 & 0.89 & 68 & 2.38 & 0.95 \\
\hline Introjected regulation ( $\mathrm{t} 2)$ & 74 & 2.34 & 0.92 & 48 & 2.19 & 0.83 & 67 & 2.31 & 0.94 \\
\hline Change in introjected regulation & 73 & -0.05 & 0.76 & 46 & -0.01 & 0.83 & 65 & -0.08 & 0.68 \\
\hline Identified regulation $(\mathrm{t} 1)$ & 77 & 3.69 & 0.77 & 48 & 3.61 & 0.73 & 69 & 3.79 & 0.69 \\
\hline Identified regulation (t2) & 75 & 3.46 & 0.69 & 49 & 3.29 & 0.72 & 65 & 3.46 & 0.73 \\
\hline Change in identified regulation & 74 & -0.22 & 0.55 & 47 & -0.31 & 0.7 & 64 & -0.32 & 0.55 \\
\hline Integrated regulation $(\mathrm{t} 1)$ & 78 & 3.23 & 0.94 & 49 & 2.92 & 0.84 & 70 & 3.21 & 0.87 \\
\hline Integrated regulation ( $\mathrm{t} 2$ ) & 76 & 3.09 & 0.87 & 49 & 2.77 & 0.9 & 67 & 3.19 & 1.00 \\
\hline Change in integrated regulation & 76 & -0.17 & 0.63 & 48 & -0.13 & 0.83 & 67 & 0 & 0.79 \\
\hline
\end{tabular}


We conducted a multivariate analysis of variance (MANOVA) with self-reported self-efficacy regarding presentation skills and the motivational variables (external regulation, introjected regulation, identified regulation and integrated regulation) as within-subject factors and condition (WGO, GO and IGO) as between-subjects variable, $F(10,334)=1.018, p=0.428$; Wilk's $\lambda=0.942$. Consequently, the conditions yielded no differences in the variables. In addition, one-way between subject ANOVAs were conducted to scrutinise the impact of the conditions on the different determinants.

\section{Self-efficacy of giving a presentation}

The pre-test results indicate that participants from the three conditions possessed a similar level of self-efficacy of presenting at the pre-test $[F(2,195)=1.705, p=0.185]$. This finding guarantees that the conditions are comparable and the groups can be employed for analysis in our research. When we study the results from the post-test, we discover that there is no difference in the self-reported self-efficacy of presenting across conditions $[F(2,188)=1.823, p=0.164]$.

\section{Motivational variables}

When we look at the self-reported self-efficacy of the IT skills needed to complete the assignment, we discover that all groups share a similar background concerning this $[F(2,187)=0.513, p=0.599]$. This indicates that prior knowledge of the website cannot be interpreted as a factor having an impact on the dependant variable. Additionally, all conditions spent a comparable length of time on creating their presentations $[F(2,182)=0.399, p=0.672]$. A closer study of how these minutes are used displays a varied image. On the one hand, there is a statistically significant difference between groups, when we study the percentage of time spent on content $[F(2,189)=4.693, p=0.010]$ and design issues of the presentation $[F(2,189)=4.775$, $p=0.009]$. Post hoc comparisons using the Tukey HSD test shows that the mean scores for the IGO group on content $(M=36.81, \mathrm{SD}=19.29)$ and $(M=50.1, \mathrm{SD}=36.81)$ were significantly different than the WGO condition's results on content $(\mathrm{SD}=45.84$, $\mathrm{SD}=16.62)$ and design $(M=40.34, \mathrm{SD}=16.92)$. On the other hand, the GO condition did not differ from the WGO and IGO groups regarding time spent on content $(M=38.31, \mathrm{SD}=21.05)$ or design $(M=46.43, \mathrm{SD}=21.59)$.

Regarding the motivational variables, there was no significant impact of the type of instruction in the different conditions. At the post-test, similar results were retrieved for the first three determinants. However, there was a significant impact on the integrated regulation at the $p<0.05$ level $[F(2,189)=3.206, p=0.043]$. Post hoc comparisons using the Tukey HSD test indicate that the mean score for the condition with instruction with interconnected $\mathrm{GO}(M=3.19, \mathrm{SD}=1.00)$ was significantly different than the condition with the instruction with non-interconnected graphic organisers $(M=2.77, \mathrm{SD}=0.90)$. The condition with instruction without $\mathrm{GO}(M=3.09$, $\mathrm{SD}=0.87$ ) however did not significantly differ from the other two conditions.

\section{Results (after coding)}

To detect whether the participants' presentations met the requirements set during the seminar, we examined the products qualitatively. Two coders first checked if the participants had made their presentation publicly accessible. Despite detailed 


\section{J. Casteleyn et al.}

instructions during the experiments and a number of reminder e-mails, not all students corrected this mistake, resulting in a lower number of participants in this analysis (analysis 1: 199 vs. analysis 2: 177).

Following this, the coders determined if a presentation fitted into one of three categories: a set of frames without any graphic organisers (NGO), a set of frames with a number of graphic organisers included (NIGO) and interconnected graphic organisers (IGO). Graphic organisers were defined as non-linguistic representations via lines, arrows, circles and/or rectangular shapes. Cohen's kappa among coders regarding this was $0.896(p<0.001)$, which refers to a consistent agreement. Figures 5,6 and 7 are products from the experiment and illustrate the different categories.

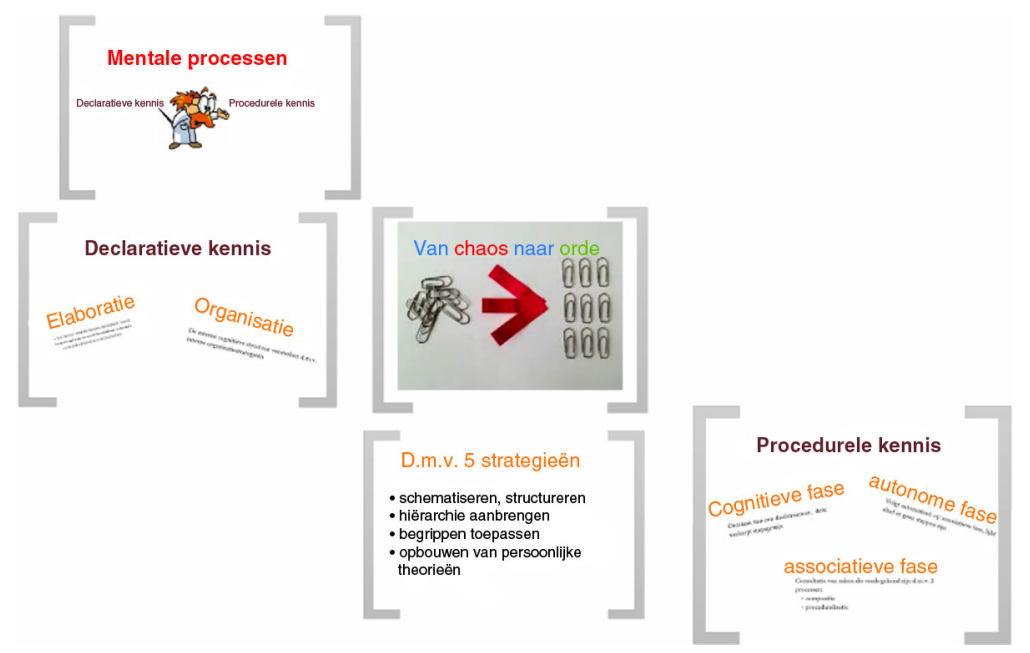

Figure 5. Presentation without graphic organisers (WGO).
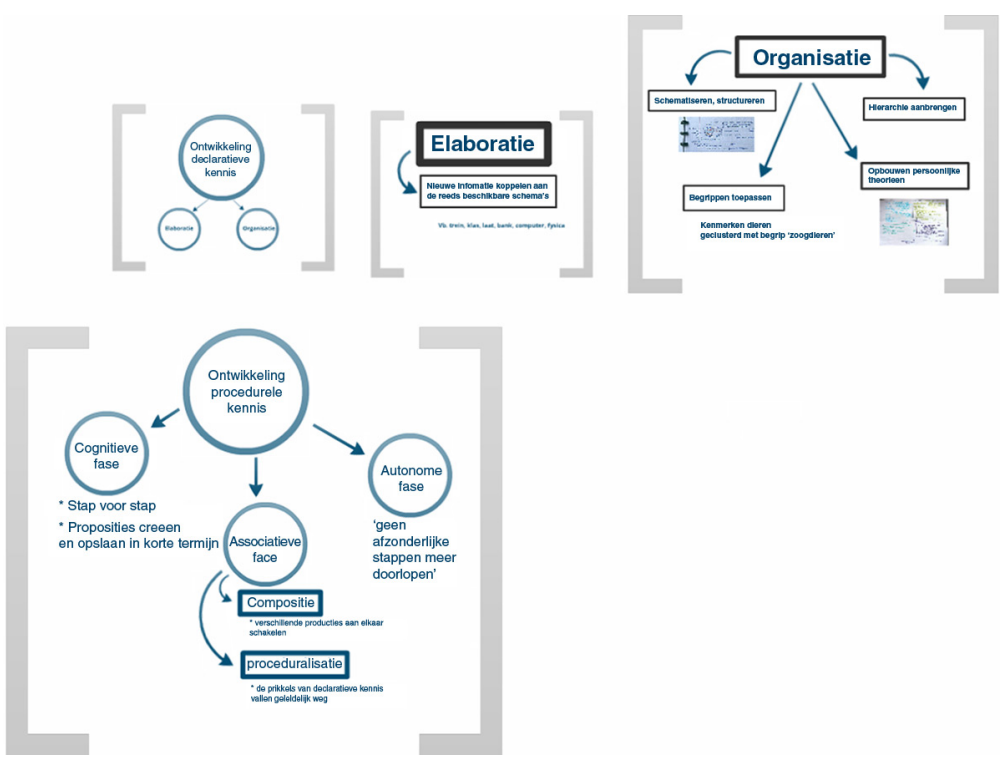

Figure 6. Presentation with graphic organisers limited to frames (GO). 


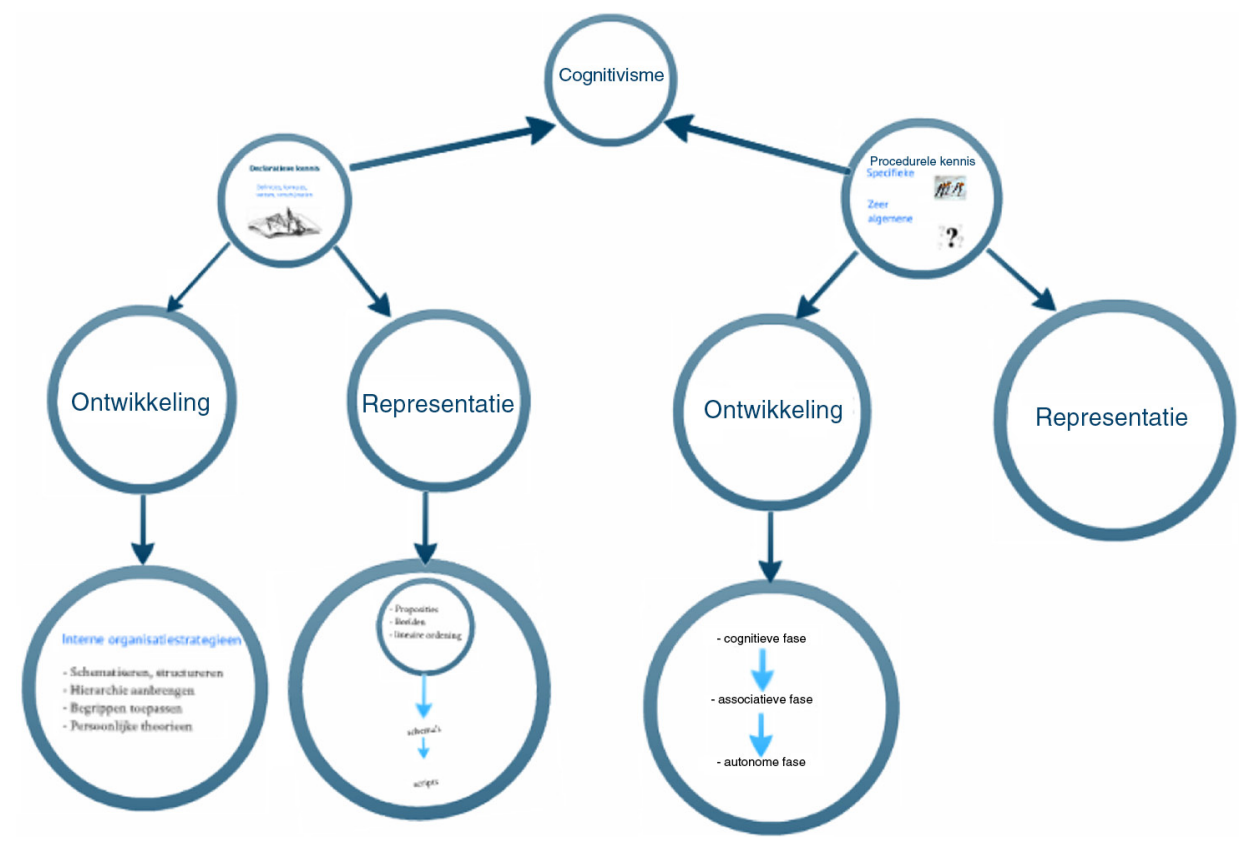

Figure 7. Presentation with interconnected graphic organisers (IGO).

The first (WGO) and second categories (GO) were further analysed. We focused on the number of frames used in the presentations (WGO and GO), the number of frames of which at least two thirds of the frames consist of graphic organisers (GO) and the type of graphic organiser deployed (GO). The inter-rater reliability regarding this was found to be kappa $=0.614(p<0.001)$, which indicates a substantial agreement. Tables 2 and 3 summarise the results. There is a significant difference concerning the number of frames being used; $t(104)=-2.24, p=0.27$. The GO presentations use more frames $(M=5.18, \mathrm{SD}=2.87)$ to display the information than the NGO products $(M=3.64, \mathrm{SD}=2.89)$. In the GO category, the Concept Pattern Organiser was the most popular to integrate in the presentation.

Table 2. Numbers of frames used per presentation.

\begin{tabular}{lccc}
\hline Category & $N$ & $M$ & SD \\
\hline Without graphic organisers (WGO) & 22 & 3.64 & 2.89 \\
Graphic organisers (GO) & 84 & 5.18 & 2.87 \\
\hline
\end{tabular}

Table 3. Type of graphic organisers deployed per presentation.

\begin{tabular}{lcccc}
\hline$(n=84)$ & Min & Max & $M$ & SD \\
\hline Conceptual/descriptive pattern organiser & 0 & 6 & 0.5 & 1.02 \\
Generalisation/principle pattern organiser & 0 & 5 & 0.45 & 0.94 \\
Time-sequence pattern organiser & 0 & 1 & 0.04 & 0.19 \\
Episode pattern organiser & 0 & 3 & 0.42 & 0.64 \\
Process/cause-effect organiser & 0 & 2 & 0.06 & 0.28 \\
Concept pattern organiser & 0 & 4 & 0.99 & 1.02 \\
\hline
\end{tabular}




\section{J. Casteleyn et al.}

When we organise the data via the coding system (WGO, GO and IGO), we obtain a different overview of the descriptive statistics for the different variables at test moment 1 and 2 (see Table 4). This table also summarises the number of minutes spent on the assignment and the self-reported percentages on content, design and other items.

We conducted a MANOVA with self-reported self-efficacy regarding presentation skills and the motivational variables as within-subject factors and the coding category (WGO, GO and IGO) as between-subjects variable, $F(10,310)=1.644, p=0.094$; Wilk's $\lambda=0.902$. Consequently, the coding yielded no differences in the variables.

In addition, one-way between subject ANOVAs were conducted to scrutinise the impact of the conditions on the different determinants. In contrast with the results based upon the conditions, the results of these analyses also showed no differences across categories.

\section{Discussion}

This study explored the impact of creating interconnected graphic organisers on selfreported self-efficacy regarding giving a presentation and on the externally motivated behaviour to train this competence in general and the integration regulation more specifically.

\section{The impact on self-efficacy}

Across conditions (first analysis) or types of presentations (second analysis), no difference in self-reported self-efficacy could be detected. This is remarkable. Borrowing

Table 4. Descriptive results (after coding).

\begin{tabular}{|c|c|c|c|c|c|c|c|c|c|}
\hline & \multicolumn{3}{|c|}{$\begin{array}{l}\text { Without graphic } \\
\text { organisers (WGO) }\end{array}$} & \multicolumn{3}{|c|}{$\begin{array}{c}\text { Graphic } \\
\text { organisers limited } \\
\text { to frames }(\mathrm{GO})\end{array}$} & \multicolumn{3}{|c|}{$\begin{array}{c}\text { Interconnected } \\
\text { graphic organisers } \\
\text { (IGO) }\end{array}$} \\
\hline & $n$ & $M$ & SD & $n$ & $M$ & SD & $n$ & $M$ & SD \\
\hline otal time spent (minutes) & 22 & 73.59 & 10.75 & 82 & 74.49 & 10.84 & 67 & 73.28 & 16.28 \\
\hline Time & 22 & 38.23 & 17.36 & 84 & 42.99 & 18.81 & 71 & 37.11 & 20.07 \\
\hline Time spent on design $(\%)$ & 22 & 45.29 & 16.52 & 84 & 44.59 & 18.35 & 71 & 47.62 & 21.53 \\
\hline Time spent on other times $(\%)$ & 21 & 8.03 & 6.61 & 81 & 8.33 & 8.37 & 69 & 8.99 & 7.67 \\
\hline cy presenting $(\mathrm{t} 1)$ & 22 & 63.54 & 14.03 & 84 & 62.03 & 16.28 & 71 & 64.83 & 13.55 \\
\hline Self-efficacy presenti & 22 & 61.15 & 15.68 & 83 & 58.22 & 13.84 & 71 & 60.33 & 11.01 \\
\hline Change in self-efficacy presenting & 22 & -2.39 & 20.95 & 83 & -3.78 & 17.66 & 71 & -4.5 & 13.26 \\
\hline Exte & 22 & 2.67 & 0.71 & 84 & 2.74 & 0.84 & 71 & 2.59 & 0.73 \\
\hline External regulation $(\mathrm{t} 2)$ & 22 & 2.9 & 0.59 & 83 & 2.6 & 0.94 & 71 & 2.65 & 0.77 \\
\hline Change in external regulation & 22 & 0.23 & 0.53 & 83 & -0.14 & 0.77 & 71 & 0.06 & 0.71 \\
\hline ted reoulation $(+1)$ & 21 & 2.81 & 1.04 & 83 & 2.32 & 0.91 & 68 & 2.32 & 0.92 \\
\hline Int 1 & 22 & 2.58 & 0.71 & 82 & 2.19 & 0.93 & 1 & 2.36 & 0.90 \\
\hline gulation & 21 & -0.2 & 0.67 & 81 & -0.12 & 0.74 & 68 & 0.05 & 0.79 \\
\hline Identi & 21 & 3.46 & 0.86 & 81 & 3.65 & 0.75 & 71 & 3.81 & 0.69 \\
\hline Identified regulation (t2) & 22 & 3.3 & 0.69 & 83 & 3.41 & 0.71 & 69 & 3.47 & 0.74 \\
\hline Change in identified regulation & 21 & -0.19 & 0.56 & 80 & -0.21 & 0.63 & 69 & -0.34 & 0.57 \\
\hline Integrated regulation $(\mathrm{t} 1)$ & 22 & 3.07 & 0.91 & 84 & 3.06 & 0.91 & 70 & 3.26 & 0.88 \\
\hline Integrated regulation (t2) & 22 & 2.93 & 0.95 & 84 & 2.95 & 0.89 & 71 & 3.22 & 0.97 \\
\hline Change in integrated regulation & 22 & -0.14 & 0.71 & 84 & -0.11 & 0.7 & 70 & -0.03 & 0.78 \\
\hline
\end{tabular}


the concepts from McLuhan's (1964) media theory, one might have guessed that the tool of the graphic organisers would not only have shaped and controlled the scale and form of the presentation's visual aids, but also the self-reported self-efficacy regarding giving a presentation. However, this study's results indicate that creating graphic organisers on an infinite canvas does not have an impact on presentation skills in the short term or that this influence goes below surface level.

Initially, the finding from this study seems to contradict other research, which report on the beneficial impact of creating graphic organisers. However, no other research has studied creating graphic organisers in the context of a multimedia presentation we can safely claim that giving a presentation is too complex a competence to see results in the short term when only one element of this competence is being trained in a limited length of time. It is also possible that participants from the IGO condition experienced an increase in presentation skills, but due to the unfamiliar IT context, they felt less confident regarding this. Our choice of self-reported selfefficacy as dependent variable would then have impeded them from reporting this increase correctly. Moreover, slides, or frames as they are called in our study, could be considered to be a type of graphic organiser, namely frames which are invisibly interconnected in a linear way. As such, our study does not unquestionably compare creating interconnected graphic organisers to different types of designing presentations, but it is possible that this paper examines different types of graphic organisers. Finally, Moreno and Valdez (2005) have hinted at another explanation. Compared to the invariable set of slides, creating graphic organisers on an infinite canvas is cognitively more demanding, because you are required to generate a new combination of graphic organisers every time. This might lower the immediate beneficial impact of creating interconnected graphic organisers.

\section{The impact on motivation}

Across groups and conditions, the impact on the motivational variables was insignificant, except for the integrated regulation in the first analysis. The IGO condition scored better than the GO condition at test moment 2. This shows that providing students with user-friendly software to create graphic organisers but limiting them to a set of frames lowers the feeling of enjoyment when preparing a presentation. This result could not be detected among WGO participants, because their condition probably bore many similarities with the slideware software they are familiar with. It can therefore be suggested that the instruction with non-interconnected graphic organisers is inadvisable in education.

\section{The impact on the content of the presentation and the design process}

Another interesting finding is related to the time spent on the different components of the presentation. First, $36 \%$ of preparation time is mostly spent on design and animation (Thielsch and Perabo 2012), which suggests that slideware software induces users to work on the non-content part of their presentation, whereas in our study, all conditions and groups score higher. However, in our questionnaire, we included 'structuring the presentation' in design features, which may distort the comparison. Second, compared to the WGO group, the IGO group spent statistically significant more time on design and less on content. This result could no longer be detected in the second analysis though. It can be that some participants of the WGO 


\section{J. Casteleyn et al.}

condition spontaneously created graphic organisers within their frames, which brought their entries into the GO group with the second analysis. After coding, the scores related to time are nearly identical across all groups, which suggests that these participants must have spent more time on content than their fellow students from the WGO condition. Accordingly, spontaneous use of graphic organisers apparently generates more time being spent on content. This implies that knowing how to use graphic organisers helps students focus on the content of a presentation. Educators should therefore train students in this skill, but it should also be acknowledged that learning how to represent information via graphic organisers needs more training than provided in the experiment. When creating presentations, designing the visual aids often generates new relationships in the content to be formed in the mind of the presenter, which eventually leads to further changes in the design. Content and design thus mutually influence each other.

\section{Further research and conclusion}

Further research could concentrate on a longer training in creating graphic organisers to increase its impact on the presentation skills. However, the 2.5 hours of the experiment already reflect the length of time available to most educators to train this specific skill. In addition, future studies may benefit from incorporating the aspect of (prior) knowledge into the research design. Moreover, this research is largely based upon participants who rate the self-efficacy regarding presentation skills themselves. To increase the validity, it might therefore be interesting to integrate other research instruments than self-reported self-efficacy into studies which investigate the impact of creating graphic organisers on presenters. Finally, in order to better understand how a presentation is created, the design process could become the centre of researchers' attention. They could, for instance, look into the minds of the presenters by conducting think aloud studies.

Above all, the research results clearly demonstrate that the true challenge for today's presenters lies in creating good presentation slides and delivering a good talk and especially 'the interaction between the software product, the preparation of the slides and the behaviour of the speaker' (Thielsch and Perabo 2012) should become the focus of further research.

\section{References}

Bandura, A. (1977) 'Self-efficacy: toward a unifying theory of behavioral change', Psychological Review, vol. 84, no. 2, pp. 191-215.

Casteleyn, J. \& Mottart, A. (2012) 'Presenting material via graphic organizers in science classes in secondary education', Procedia - Social and Behavorial Sciences, vol. 69, pp. 458-466.

Casteleyn, J., Mottart, A. \& Valcke, M. (2013) 'The impact of graphic organizers on learning from presentations', Technology, Pedagogy and Education, vol. 22, pp. 283-301.

Chou, M.-H. (2011) 'The influence of learner strategies on oral presentations: a comparison between group and individual performance', English for Specific Purposes, vol. 30, pp. 272-285.

Deci, E. \& Vansteenkiste, M. (2004) 'Self-determination theory and basic need satisfaction: understanding human development in positive psychology', Ricerche di Psicologia, vol. 27, no. 1, pp. 23-40.

De Grez, L., Valcke, M. \& Roozen, I. (2009a) 'The impact of goal orientation, self-reflection and personal characteristics on the acquisition of oral presentation skills", European Journal of Psychology of Education, vol. 24, no. 3, pp. 293-306. 
De Grez, L., Valcke, M. \& Roozen, I. (2009b) 'The impact of an innovative instructional intervention on the acquisition of oral presentation skills in higher education', Computers \& Education, vol. 53, pp. 112-120.

Graham, S. \& Weiner, B. (1996) 'Theories and principles of motivation', in Handbook of Educational Psychology, eds. D. C. Berliner \& R. C. Calfee, Macmillian, New-York, pp. $63-84$.

Lambiotte, J. \& Dansereau, D. (1992) 'Effects of knowledge maps and prior knowledge on recall of science lecture content', Journal of Experimental Education, vol. 60, no. 3, pp. 189-201.

Marzano, R., Pickering, D. \& Pollock, J. (2001) Classroom Instruction That Works: ResearchBased Strategies for Increasing Student Achievement, Association for Supervision and Curriculum Development, Alexandria, VA.

Mayer, R. (2009) Multimedia Learning. 2nd edn, Cambridge University Press, New York.

McLuhan, M. (1964) Understanding Media - The Extensions of Man, McGraw-Hill, New York.

Moreno, R. \& Valdez, A. (2005) 'Cognitive load and learning effects of having students organize pictures and words in multimedia environments: the role of student interactivity and feedback', Educational Technology Research and Development, vol. 53, no. 3, pp. 35-45.

Nesbit, J. \& Adesope, O. (2006) 'Learning with concept and knowledge maps: a meta-analysis', Review of Educational Research, vol. 76, no. 3, pp. 413-448.

N.N. (2012). Learn Prezi, [online] Available at: http://ww.prezi.com/learn

Novak, J. (1990) 'Concept mapping: a useful tool for science education', Journal of Research in Science Teaching, vol. 27, pp. 937-949.

Novak, J. (2010) 'Learning, creating, and using knowledge: concept maps as facilitative tools in schools and corporations', Journal of e-Learning and Knowledge Society, vol. 6, no. 3, pp. 21-30.

Ryan, R. \& Deci, E. (2000) 'Self-determination theory and the facilitation of intrinsic motivation, social development, and well-being', American Psychologist, vol. 55, no. 1, pp. 68-78.

Shaw, S., et al., (2012) 'Graphic organizers or graphic overviews? Presentation order effects with computer-based text', Educational Technology Research and Development, vol. 60 , pp. 807-820.

Thielsch, M. \& Perabo, I. (2012) 'Use and evaluation of presentation software', Technical Communication, vol. 59, no. 2, pp. 112-123.

Tsai, S.-C. (2010) 'Developing and integrating courseware for oral presentations into ESP learning contexts', Computers \& Education, vol. 55, pp. 1245-1258.

Vansteenkiste, M., et al., (2009) 'Motivational profiles from a self-determination perspective: the quality of motivation matters', Journal of Educational Psychology, vol. 101, pp. 671-688. 